\title{
Down-Regulation of miR-3928 Promoted Osteosarcoma Growth
}

\author{
Haidong Xua, Xiaozhou Liua Jianning Zhao ${ }^{a}$ \\ aDepartment of Orthopedics of Jinling Hospital, Nanjing University, School of Medicine, Nanjing, China; \\ ${ }^{\mathrm{b}}$ These authors contributed equally to this work
}

\author{
Key Words \\ miR-3928 • Osteosarcoma • Tumor growth • Therapy
}

\begin{abstract}
Background: Osteosarcoma is the most common primary bone malignancy in children and young adults. Most failures of osteosarcoma treatment were due to resistance to chemotherapy. Development of new therapy required elucidation underlying molecular mechanism. Many miRNAs have been proved to be involved in the pathogenesis of osteosarcoma. Methods: MiR-3928 expression level was assayed by qRT-PCR. MiRNA mimics or ASO were transfected for up-regulation or down-regulation of miR-3928 expression. Cell proliferation was assayed by formazan test. Apoptosis and cell cycle were assayed by FACS. MiR-3928 targeted genes were predicated by bioinformatics algorithm (TargetScanHuman). The correlation between targeted gene and miR-3928 was analyzed by Pearson's correlation coefficient analysis. Results: MiR-3928 was down-regulated in osteosarcoma tissues. Over-expression of miR-3928 inhibited tumor growth, induced cell apoptosis, increased the percent of cells in G1 phrase and decreased the percent of cells in S phrase. Down-regulation of miR-3928 promoted cell proliferation. ERBB3, IL-6R and CDK6 may be the targeted genes of miR-3928. Conclusions: Down-expression of miR-3928 in osteosarcoma promoted tumor growth by targeting ERBB3, IL-6R and CDK6. MiR-3928 may be a potential therapy target worth further investigation.
\end{abstract}

Copyright (C) 2014 S. Karger AG, Basel

\section{Introduction}

Osteosarcoma is the most common primary bone malignancy [1]. Osteosarcoma predominately affects adolescents and young adults [2]. The predominant therapy of osteosarcoma is multiagent chemotherapy, and the prognosis is very poor [3-8]. 
Development of new effective therapy required elucidation of the pathogenesis of osteosarcoma and identification of new therapy target. Accumulating evidence indicated that microRNAs were involved in the pathogenesis of cancer [9].

MicroRNAs (miRNAs) are a class of highly conserved short noncoding small RNAs, usually 18-25 nucleotides in length, which inhibit translation and cleave mRNA by base-pairing to the 3' untranslated region of the target genes [10-12]. It has been well demonstrated that deregulation or dysfunction of miRNAs contributed to cancer development [13].

MiR-3928 is implicated in cellular response to ionizing radiation [14]. In a previous study, an oscillation was observed in the expression of both mature miR-3928 and Dicer mRNA in irradiated cells. Overexpression of miR-3928 induced DNA damage, activated Rad3-related kinase (ATR), and phosphorylated checkpoint kinase 1 (Chk1) accompanied by G1 arrest [15]. As miR-3928 could induce G1 arrest, we guessed that down-regulation of miR-3928 may play a role in the pathogenesis of cancer by promoting cell growth.

Here, we wondered whether miR-3928 was involved in the pathogenesis of osteosarcoma. Our aim is to identify the role of miR-3928 in osteosarcoma cells growth and apoptosis, and the targeted genes of miR-3928.

\section{Materials and Methods}

\section{Patients}

Surgical specimens from 10 osteosarcoma patients and matched normal control adjacent normal tissues were obtained postoperatively in 2010 from the Department of Orthopedics of Jinling Hospital, Nanjing University, School of Medicine. All patients gave signed, informed consent for their tissues to be used for scientific research. Ethical approval for the study was obtained from Jinling Hospital, Nanjing University (Shanghai, China). All diagnoses were based on pathological and/or cytological evidence. The histological features of the specimens were evaluated by senior pathologists according to the World Health Organization classification criteria. Tissues were obtained before chemotherapy and radiotherapy and were immediately frozen and stored at $-80{ }^{\circ} \mathrm{C}$ prior to qRT-PCR assay. The clinical data of these patients was listed.

\section{Cell Lines, Cell Culture}

Human osteosarcoma U20S, Saos-2 and MG63 cells and human osteoblasts h-OB cell lines were purchased from Cell Bank of Chinese (Shanghai, China) Academy of Sciences and maintained in Dulbecco's modified Eagle's medium (DMEM) supplemented with 10\% fetal bovine serum(PAA, Austria), 2 mM L-glutamine and $100 \mu \mathrm{g} / \mathrm{mL}$ penicillin/streptomycin (Bio Light, Shanghai, China). U20S, Saos-2 MG63 and HOb cells were seeded in 24 well plates at a $6 \times 10^{4}$ cells per well for following experiments.

\section{MTT assay}

For MTT (3-(4,5-Dimethylthiazol-2-yl)-2,5-diphenyltetrazolium bromide) assay, 500 cells per well were seeded in triplicate in a 96-well plate with complete growth medium. Cells were counted over 5 days using the MTT assay (Promega, Fitchburg, WI, USA) as described previously [16-18]. The data were measured by Microtiter plate reader 570-nm filters (Promega, USA).

\section{Apoptosis assay}

$24 \mathrm{~h}$ after transfection, cells were labeled with Annexin V-FITC and propidium iodide (PI) using an apoptosis detecting kit (Invitrogen, Canada) following the manufacturer's instructions. Samples were determined by FACS assays and the results were analyzed using FACS software (Becton Dickinson, San Jose, CA) [19].

\section{Cell Synchronization and cell cycle analysis}

Cells were synchronized by serum deprivation for $48 \mathrm{~h}$. Cells were harvested in the appropriate manner and washed in PBS. Cells were fixed in cold $70 \%$ ethanol for $30 \mathrm{~min}$ at $4^{\circ} \mathrm{C}$. Then cells were washed twice in PBS. $50 \mu \mathrm{l}$ of a $100 \mu \mathrm{g} / \mathrm{ml}$ sock of RNase was added. At last $200 \mu \mathrm{l} \mathrm{PI} \mathrm{(from} 50 \mu \mathrm{g} / \mathrm{ml}$ stock solution) was added. Cell cycle was analyzed as described previously [20]. 
Table 1. Clinical data of patients

\begin{tabular}{lllllll}
\hline No & Sex & Age & Source & Site & Stage & Date of Diagnose \\
\hline 1 & F & 4 & primary osteosarcoma & proximal tibia & II & $5 / 3 / 2010$ \\
2 & M & 5 & primary osteosarcoma & shoulder & II & $4 / 11 / 2010$ \\
3 & F & 15 & primary osteosarcoma & femur & II & $5 / 2 / 2010$ \\
4 & F & 5 & primary osteosarcoma & Knee & II & $3 / 3 / 2010$ \\
5 & M & 27 & primary osteosarcoma & knee & II & $19 / 3 / 2010$ \\
6 & M & 14 & primary osteosarcoma & distal of femur & II & $20 / 1 / 2010$ \\
7 & M & 19 & primary osteosarcoma & proximal tibia & II & $20 / 4 / 2010$ \\
8 & M & 10 & primary osteosarcoma & femur & II & $17 / 1 / 2010$ \\
9 & F & 13 & primary osteosarcoma & proximal tibia & II & $14 / 2 / 2010$ \\
10 & F & 11 & primary osteosarcoma & femur & II & $19 / 5 / 2010$ \\
\hline
\end{tabular}

RNA extraction and Real time $q-P C R$

RNA was extracted with Trizol reagent (Invitrogen, Carlsbad, CA, USA) according to the manufacturer's protocol. The cDNA synthesis and real-time qPCR were subsequently performed

using the Qiagen system as described detail in our previous studies $[18,21,22]$. Real-time quantitative PCR analysis was performed using standard protocols on an Applied Biosystem's 7500 HT sequence Detection System. MiR-3928 expression was assessed using a mirVana ${ }^{\mathrm{TM}} \mathrm{qRT}$-PCR miRNA Detection Kit (Ambion, USA). The primers were designed and synthesized by Shengong Company (Shanghai). The primers of potential target genes were list: ERBB3, F AAGGCCCTTTAATGTGGGGG, R CTCCCATCAGACAACAGTGCT; CDK6 F CTGCAGGGAAAGAAAAGTGCAA, R CAAGACTTCGGGTGCTCTGT; CDK13 F AGGCTCTTCAGTGCGAGTTC, R TGTCCAGGGCCTGTTTTTACA; IL-6R F TCACTGTGTCATCCACGACG; R AGCCAGCTATCTGGGGAAGA; MLL2 F GGCCAAATGGGAAGCAACTG, R GACGTGTGTCCACTCGTTCT; GAPDH F CGCTCTCTGCTCCTCCTGTT, $\mathrm{R}$ CCATGGTGTCTGAGCGATGT. U6 F GTGGACCGCACAAGCTCGCT, R TTGTTGAACGGCACTGTGTATAGCA.

\section{Luciferase reporter assay}

The 3'UTR reporter plasmid (RL-control, RL- ERBB3, RL-CDK6, RL-CDK13, RL-IL-6R and RL-MLL2) were constructed by Shengong Company (Shanghai). RL reporter plasmids (3.6fmol) and pGL3-control (500ng for normalization; Promega) were transfected with Lipofectamine 2000 (Invitrogen) into HEK293 cells $\left(6 \times 10^{4}\right.$ cells per well). Cells were collected after $48 \mathrm{~h}$ for assay using the Dual Luciferase reporter assay system (Promega) [23]. The primers for 3'UTR cloning were list: ERBB3, F GCTTCTTCACAGGCACTCCT, R GGATGTGGCTGTTGGGGTTA; CDK6 F ACACCCTTGGTGGCTTATGG, R AGGCGGTTTCCTTGGAGAAG; CDK13 F GGCATAAGCCTTTTATGGCCC, R GGGAGGGGCTGTTTGTTACAT; IL-6R F GGGAAAAACCAGCGTGTGAC; R ATCCTTTCGCACCTGTCTGG; MLL2 F CCCACAGGAACCGCTGTAAT, R CCAATCTCCCCCTCCCTGTA

\section{MiRNAs mimics and miRNAs antisense oligonucleotides transfection}

MiR-3928, miRNAs mimics and miRNAs antisense oligonucleotides (ASO) were obtained from GenePharma (GenePharma, China). MiRNAs mimics, ASO, negative control (NC) were transfected into cells at a concentration of 50nM using Lipofectamine 2000 (Invitrogen, Canada) transfection reagent according to the manufacturer's instructions. $48 \mathrm{~h}$ later cells were collected for further experiments. The sequence of mimics and ASO were list: Mimics GGAGGAACCUUGGAGCUUCGGC, Antisense oligonucleotides UGAAGCUCUAAGGUUCCGCCUGC; NC sense strand UUCUCCGAACGUGUCACGUTT; NC antisense strand, ACGUGACACGUUCGGAGAATT

MicroRNAs targets prediction

TargetScanHuman (http://www.targetscan.org/vert_61/) [24-27] and miRbase [28] is applied to identify the potential target of miR-3928. The script of miR-3928 was list : 37-ggaggaaccuuggagcuucggc- 58 .

Statistical Analysis

Data were presented as the mean \pm s.d (standard deviation). from at least three independent experiments. The difference between two groups was analyzed using two-tailed Student's $t$ test. Correlation 


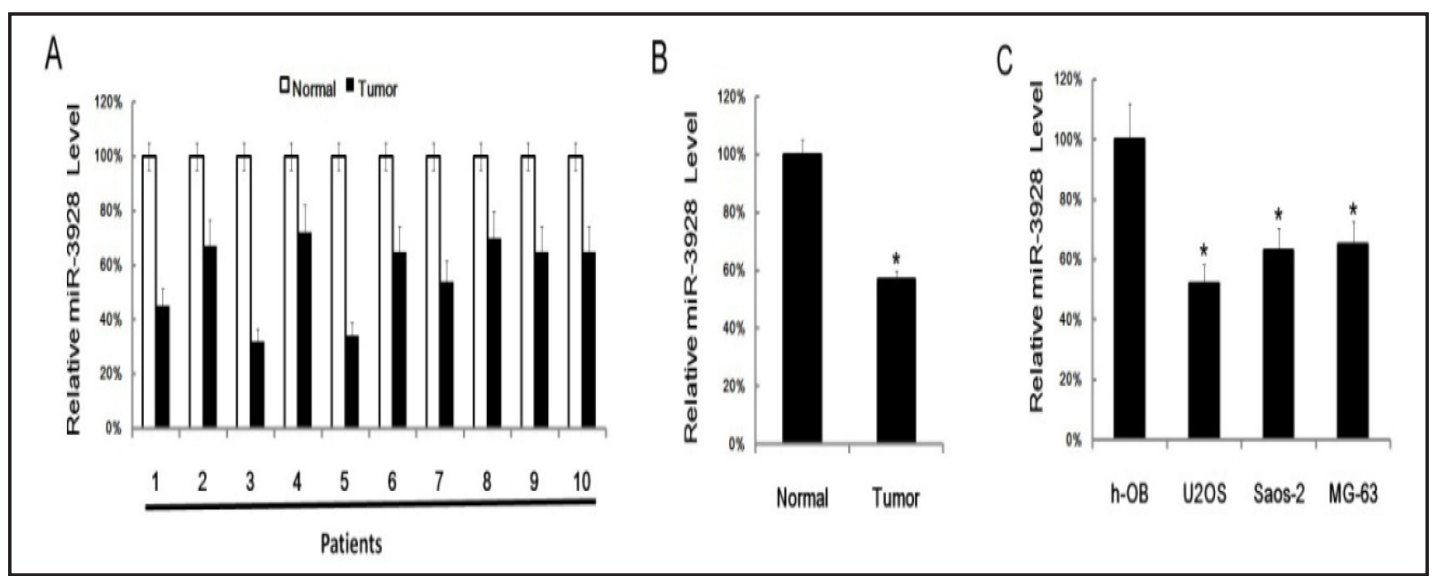

Fig. 1. Low- expression of miR-3928 in osteosarcoma tissues and osteosarcoma cell lines. 10 pairs of tumor tissues and adjacent normal tissues from 10 patients were assayed by qRT-PCR separately, Data were normalized to U6 small nuclear RNA, the miR-3928 expression in normal tissues were arbitrarily defined as $100 \%$, Data are mean \pm s.d. of three separate experiments (A). The mean expression of miR-3928 in tumor tissues and normal tissues, the miR-3928 expression in normal tissues were arbitrarily defined as $100 \%$, Data are mean \pm s.d. of 10 samples (B). The miR-3928 levels in h-OB, U2OS, Saos- 2 and MG-63 were assayed by qRT-PCR. The miR-3928 expression in h-OB was arbitrarily defined as $100 \%$. Data are mean \pm s.d. of three separate experiments $(\mathrm{C}) .{ }^{*} \mathrm{P}<0.05$.

analysis between genes level and miR-3928 level was performed by two-tailed Person's correlation coefficient analysis. Statistical analyses were performed using SPSS software (version 17.0). A value of $\mathrm{P}<0.05$ was considered a statistically significant difference.

\section{Results}

Down-regulation of miR-3928 in osteosarcoma

To identify the role of miR-3928 in osteosarcoma, we firstly assayed the miR-3928 level in osteosarcoma tissues and corresponding adjacent normal tissues by qRT-PCR. We found that the level of miR-3928 was lower in osteosarcoma tissue than in normal tissues in the 10 pairs (Fig. 1A). And the mean expression of miR-3928 in osteosarcoma tissues was about $60 \%$ expression level of miR-3928 in corresponding adjacent normal tissues (Fig. 1B). The miR-3928 expression in osteosarcoma cell lines was assayed by qRT-PCR. We found that osteosarcoma cell lines (U20S, Saos-2 and MG-63) showed a lower miR-3928 expression as comparing with human osteoblast cell lines (HOb) (Fig. 1C). So, miR-3928 was downregulated in vivo and in vitro in osteosarcoma.

\section{Over-expression of miR-3928 inhibited tumor growth}

To investigate the role of miR-3928 in osteosarcoma, we over-expressed the miR-3928 in U20S and MG-63 cell lines by miRNA mimics transfection. After $48 \mathrm{~h}$ transfection, miR3928 in U20S and MG-63 were over-expressed up to 6-8 folds (Fig. 2A). Then,we assayed cell proliferation, apoptosis rate and cell cycle of these two cell lines. We found that overexpression of miR-3928 inhibited U2OS and MG-63 cells proliferation (Fig. 2B). FACS analysis revealed that after miR-3928-mimics transfection, the apoptosis rates were increased in the both cell lines (Fig. 2C). Cell cycle analysis showed that mimics transfection increased the percent of cells in G1 phrase and decreased the percent of cells in S phrase. Thus our data indicated that over-expression of miR-3928 inhibited osteosarcoma cells growth. 
A

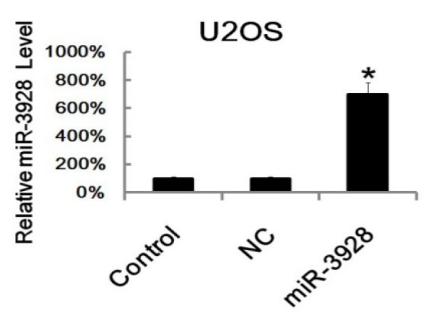

B

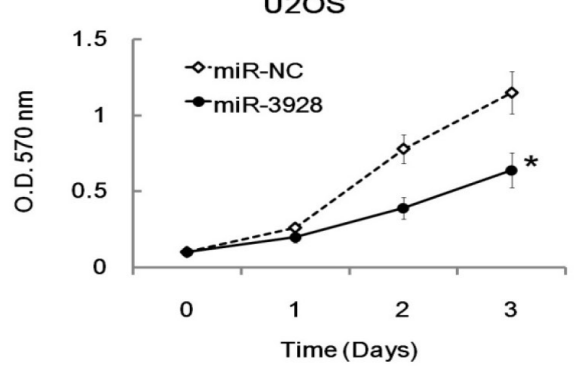

$\mathrm{C}$

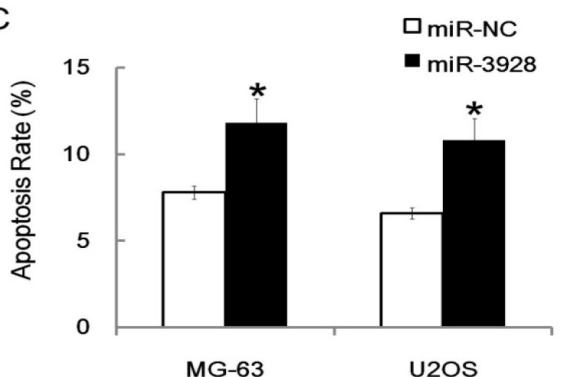

D

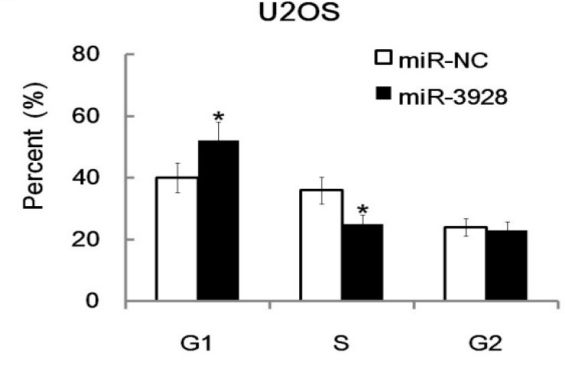

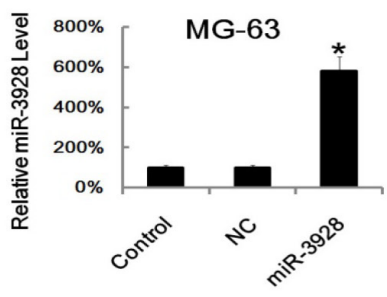

MG-63

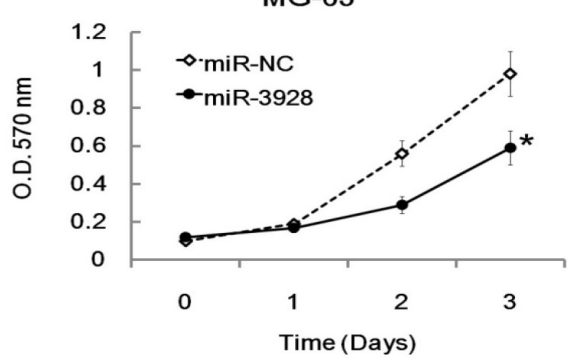

MG-63

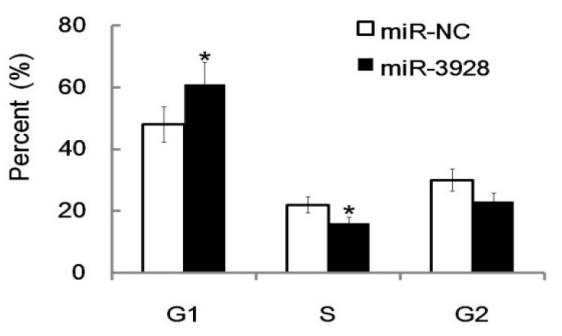

Fig. 2. Over-expression of miR-3928 inhibited osteosarcoma cell lines growth, promoted apoptosis and decreased cell numbers in S phrase. U2OS and MG-63 $\left(6 \times 10^{5}\right.$ cells/well) were transfected with miR-3928 mimics or miR-NC (NC) separately. $48 \mathrm{~h}$ later, the miR-3928 expression were assayed by qRT-PCR. Data were normalized to U6 small nuclear RNA. The miR-3928 expression in blank control was arbitrarily defined as $100 \%$. Data are mean \pm s.d. of three separate experiments (A). After miR-3928 mimics transfection, the cell proliferation was assayed by MTT at the indicted time point. Data are mean \pm s.d. of three separate experi-

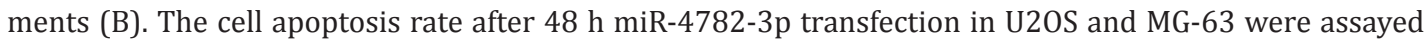
by Annex V PI-FACS analysis. The apoptosis rate in miR-NC group was arbitrarily defined as $100 \%$. Data are mean \pm s.d. of three separate experiments (C). $48 \mathrm{~h}$ after transfection, cell cycle was analyzed by FACS. The percent of G1, S and G2 phrase cells were recorded. Data are mean \pm s.d. of three separate experiments (C). ${ }^{*} \mathrm{P}<0.05$.

Down-regulation of miR-3928 promoted tumor proliferation

We then down-regulated the miR-3928 expression in U2OS and MG-63 cell lines by miRNA ASO transfection to reveal the role of miR-3928 from the other side. $48 \mathrm{~h}$ after miR- 
A

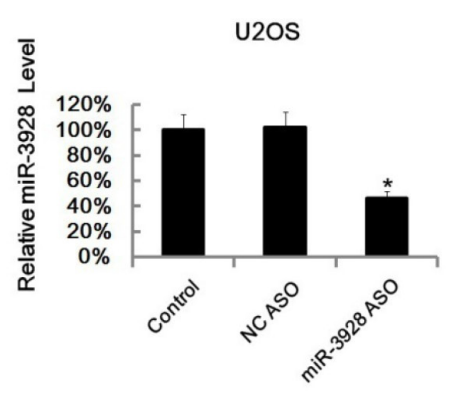

B

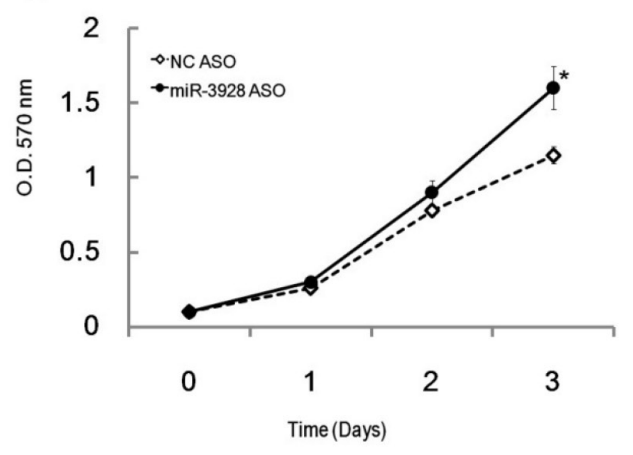

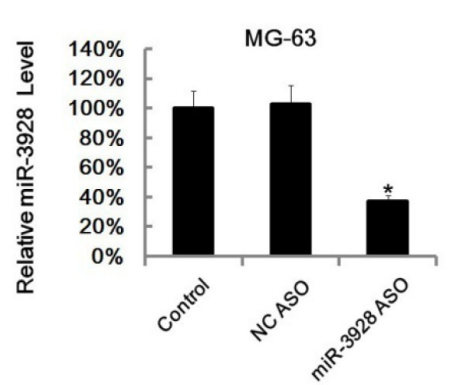

MG-63

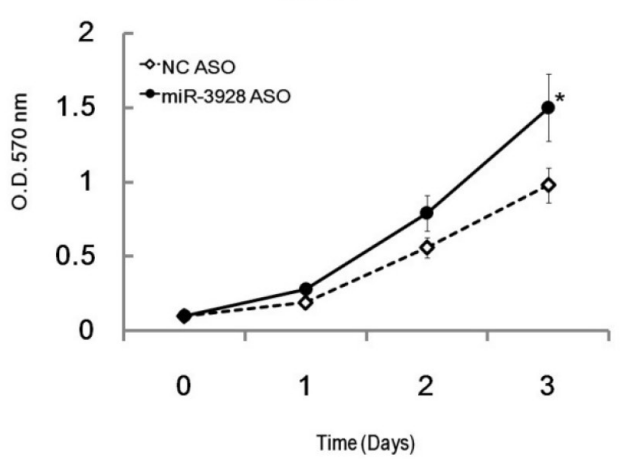

Fig. 3. Down-regulation of miR-3928 promoted tumor proliferation. U2OS and MG-63 (6×105 cells/well) were transfected with miR-3928 ASO or miR-NC ASO or blank control separately. 48h later, the miR-3928 expression were assayed by qRT-PCR. Data were normalized to U6 small nuclear RNA. The miR-3928 expression in blank control group were arbitrarily defined as $100 \%$. Data are mean \pm s.d. of three separate experiments (A). After miR-3928 ASO transfection, the cell proliferation was assayed by MTT at the indicted time point. Data are mean \pm s.d. of three separate experiments (B). ${ }^{*} \mathrm{P}<0.05$.

3928 ASO transfection, the miR-3928 in both cell lines were down-regulated (Fig. 3A). Then cell proliferation was assayed. We found that miR-3928 ASO transfection promoted cells proliferation as MTT assay indicated (Fig. 3B).

Predication targeted genes of miR-3928

The target genes of interest for miR-3928 were selected from a list in TargetScanHuman. Based on our interest, ERBB3(Erythroblastic Leukemia Oncogene Homolog 3), CDK6 (Cyclin-dependent kinase 6), CDK13 (Cyclin-dependent kinase 13), IL-6R and MLL2(mixedlineage leukemia 2), 5 putative genes were chosen for further investigation (Fig 4A). After construction, 3'UTR of the 5 genes were cloned to luciferase reporter plasmid, miR-3928 or control miRNAs with these reporter genes into HEK293 cells, we found that the expressions of ERBB3, CDK6 and IL-6R were significantly inhibited (Fig. 4B).

\section{ERBB3, IL-6R and CDK6 were inversely correlated with miR-3928 expression}

Next, we assayed the mean expression of the five genes (ERBB3, CDK6, CDK13, IL-6R and MLL2). We found that all the five genes showed higher expressions in tumor tissues than in normal adjacent control (Fig. 5A). Then, we explored the correlation between miR3928 expression level and these genes expression level in osteosarcoma tissues. After normalization, the expression level of miR-3928 and these five genes were analyzed by Pearson's correlation coefficient analysis. Significantly, ERBB3, IL-6R and CDK6 levels 
Fig. 4. MiR-3928 targeted genes predication. Putative targeted genes were predicated by bioinformatics analysis, the binding site of four putative targeted were showed (A). The RL reporter plasmids (RL-control, RLERBB3, RL-CDK6, RL-CDK13, RL-IL-6R and RL-MLL2) and miR-3928 or miR-NC were cotransfected into HEK293 cells, along with a firefly luciferase reporter (pGL control) for normalization. Luciferase activities were measured after $48 \mathrm{~h}$. Then the ratio of RL activity of firefly luciferase activity in miR-3928 treated group were calculated and compared with the ratio in miR-NC group (which was arbitrary defined as 100\%). Data are mean \pm s.d. of three separate experiments. ${ }^{*} \mathrm{P}<0.05$.

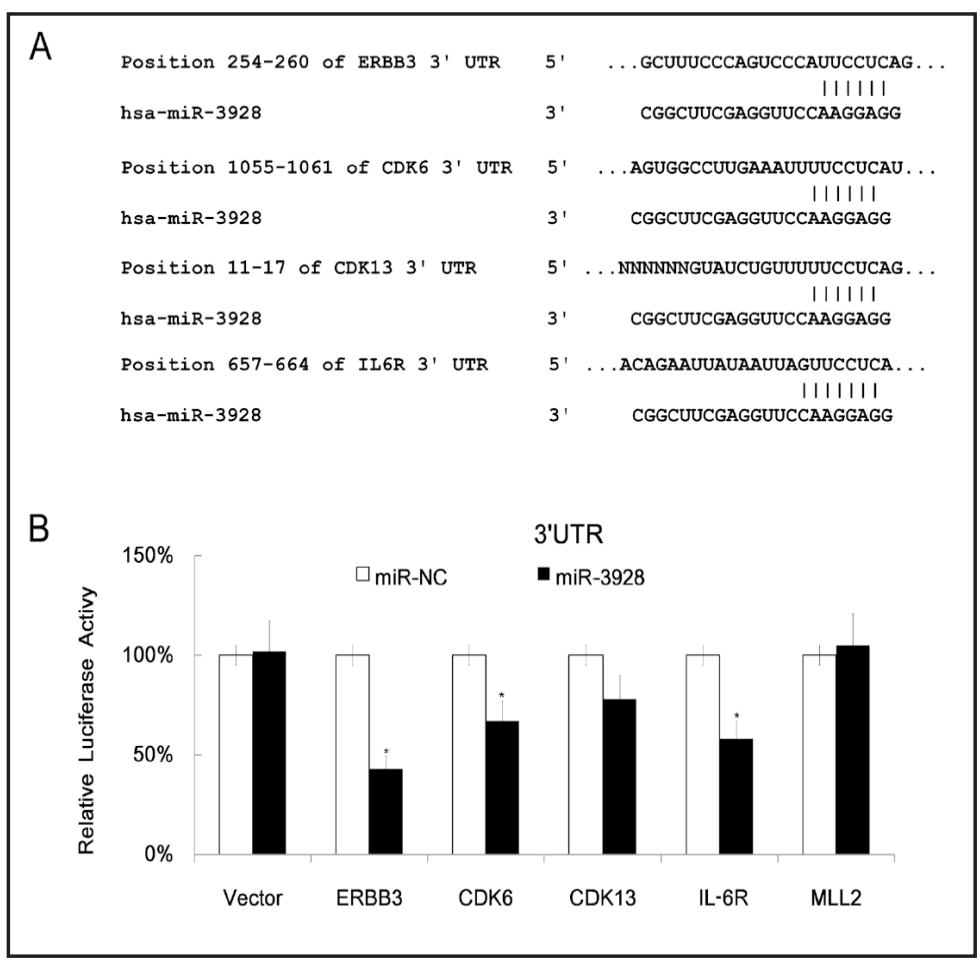

were inversely correlated with miR-3928 expression in osteosarcoma tissues (Fig. 5B). Collectively, these results implied that ERBB3, IL-6R and CDK6 in osteosarcoma tissues could be negatively regulated by miR-3928.

\section{Discussion}

This may be the first time to reveal the role of miR-3928 in cancer. We found that the anti-cancer role of miR-3928 in osteosarcoma. Our data indicated that miR-3928 may inhibited cell proliferation, induced cell apoptosis in osteosarcoma. In a previous study, ionizing radiation induced the expression of miR-3928 that suppressed Dicer expression and subsequently inhibited the maturation of miRNAs including miR-3928. The oscillation of Dicer and miR-3928 expression then provided cells a fine tuning process to respond to DNA damage and return to a balance after DNA damage is repaired, which is an important process in DNA damage signaling transduction [15]. Here, in osteosarcoma tissues, the level of miR-3928 was down-regulated, and over-expression of miR-3928 inhibited tumor growth. It seemed that in osteosarcoma, the fine tuning role of miR-3928 was gone. The reasons we concluded may be the balance of miR-3928 and Dicer were broken and the loss of Dicer function resulted the malfunction of other miRNAs. We will investigate the role of Dicer in osteosarcoma in further study.

Our data showed that the targeted genes involved were ERBB3, IL-6R and CDK6. ERBB3 belonged to the ERBB family, and played an important role in the growth of various organs [29], including the bone tissue [30,31]. The activated role of ERBB3 has been confirmed in osteosarcoma, ERBB3 expression in osteosarcoma cells increased with the incidence of metastasis, particularly in cases of recurrence, and the ERBB3 expression correlated with tumor invasion and patient outcome [32]. Our results may provide a reason why ERBB3 was up-regulated in osteosarcoma.

Interleukin-6 (IL-6) is a multifunctional cytokine which plays an important role in a wide range of biologic activities in different types of cell including tumor cells. These effects 


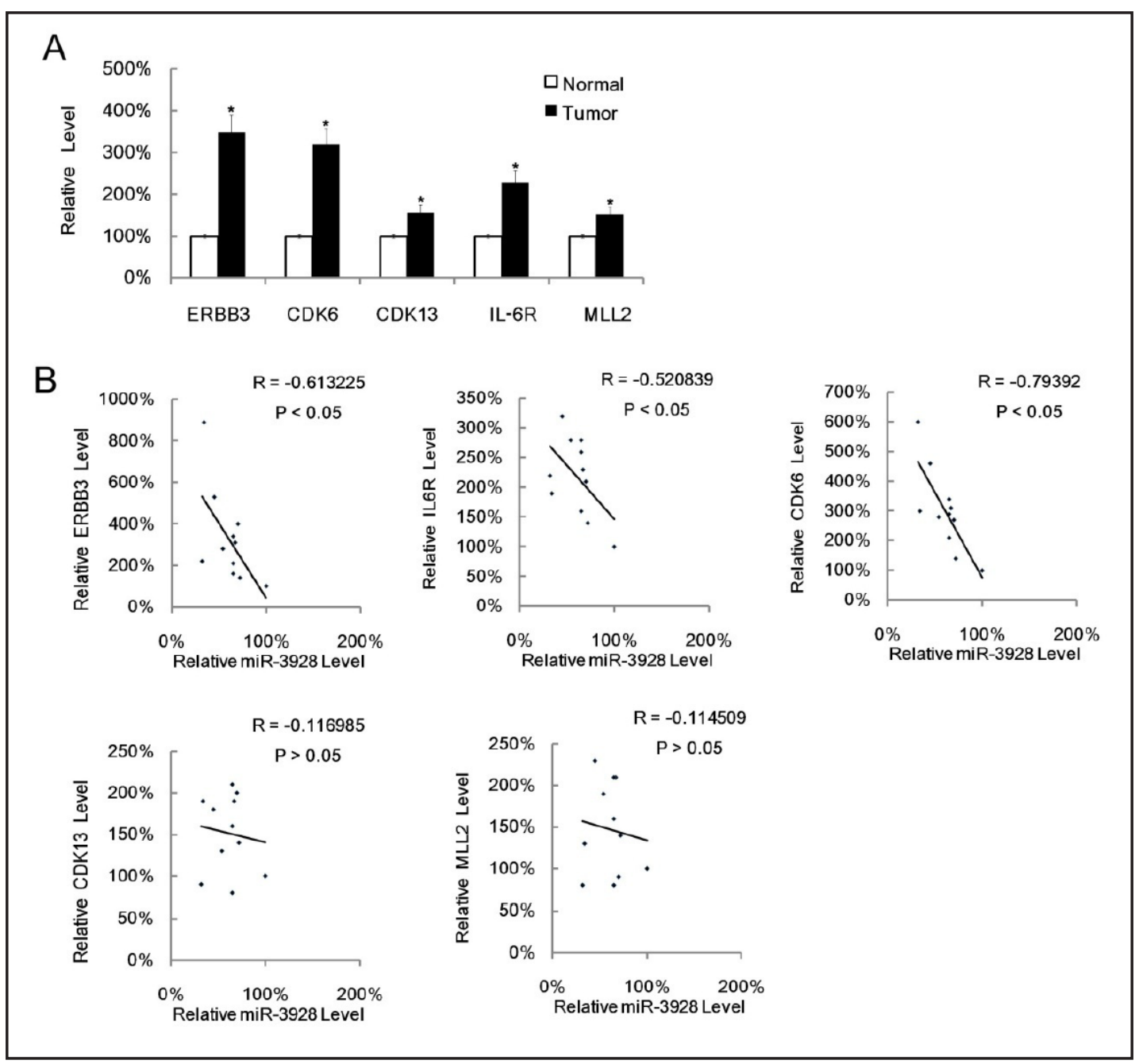

Fig. 5. ERBB3, CDK6, CDK13, IL-6R and MLL2 expression in osteosarcoma tissues were assayed by qRTPCR. Data were normalized to GAPDH, the miR-3928 expression in normal tissues were arbitrarily defined as $100 \%$, Data are mean \pm s.d. of three separate experiments (A). Inverse correlation between miR-3928 and targeted genes levels in osteosarcoma tissues $(n=10)$. Statistical analysis was performed using Pearson's correlation coefficient. Normalized miR-3928 expression and putative targeted gene expression were shown as standardized values calculated in SPSS software (B). ${ }^{*} \mathrm{P}<0.05$.

were mediated by several signaling pathways, in particular the signal transducer and transcription activator 3 (Stat3) [33, 34]. Here we found that IL-6R may be targeted by miR3928 , and the precise mechanism needed further investigation.

We found that miR-3928 up-regulation increased the percent of cells in G1 phrase and decreased the percent of cells in S phrase. The reason may be that CDK6 was targeted by miR-3928. Interestingly, recent study showed that CDK6 linked the cell cycle to tumor angiogenesis [35]. Angiogenesis is a key step of tumor growth. Therefore, we provided a hypothesis of angiogenesis of osteosarcoma: malfunction of miR-3928 leaded higher expression of CDK6, which resulted the angiogenesis of osteosarcoma.

In conclusion, we proved the inhibitory role of miR-3928 in osteosarcoma. Our study may provide a potential therapy target for osteosarcoma. 


\section{Disclosure Statement}

The authors have declared that no competing interests exist.

\section{References}

1 Ottaviani G, Jaffe N: The epidemiology of osteosarcoma. Cancer Treat Res 2009;152:3-13.

-2 Mirabello L, Troisi RJ, Savage SA: Osteosarcoma incidence and survival rates from 1973 to 2004: Data from the surveillance, epidemiology, and end results program. Cancer 2009;115:1531-1543.

-3 Bielack SS, Kempf-Bielack B, Delling G, Exner GU, Flege S, Helmke K, Kotz R, Salzer-Kuntschik M, Werner M, Winkelmann W, Zoubek A, Jurgens H, Winkler K: Prognostic factors in high-grade osteosarcoma of the extremities or trunk: An analysis of 1,702 patients treated on neoadjuvant cooperative osteosarcoma study group protocols. J Clin Oncol 2002;20:776-790.

4 Lewis VO: What's new in musculoskeletal oncology. J Bone Joint Surg Am 2009;91:1546-1556.

-5 Meyers PA, Schwartz CL, Krailo M, Kleinerman ES, Betcher D, Bernstein ML, Conrad E, Ferguson W, Gebhardt M, Goorin AM, Harris MB, Healey J, Huvos A, Link M, Montebello J, Nadel H, Nieder M, Sato J, Siegal G, Weiner M, Wells R, Wold L, Womer R, Grier H: Osteosarcoma: A randomized, prospective trial of the addition of ifosfamide and/or muramyl tripeptide to cisplatin, doxorubicin, and high-dose methotrexate. J Clin Oncol 2005;23:2004-2011.

6 Cho Y, Jung GH, Chung SH, Kim JY, Choi Y, Kim JD: Long-term survivals of stage iib osteosarcoma: A 20-year experience in a single institution. Clin Orthop Surg 2011;3:48-54.

7 Tsuchiya H, Tomita K, Mori Y, Asada N, Morinaga T, Kitano S, Yamamoto N: Caffeine-assisted chemotherapy and minimized tumor excision for nonmetastatic osteosarcoma. Anticancer Res 1998;18:657-666.

8 Bolling T, Schuller P, Distelmaier B, Schuck A, Ernst I, Gosheger G, Winkelmann W, Dirksen U, Jurgens H, Kronholz HL, Willich N, Konemann S: Perioperative high-dose rate brachytherapy using a bendy applicator (flab): Treatment results of 74 patients. Anticancer Res 2008;28:3885-3890.

-9 Calin GA, Sevignani C, Dumitru CD, Hyslop T, Noch E, Yendamuri S, Shimizu M, Rattan S, Bullrich F, Negrini M, Croce CM: Human microrna genes are frequently located at fragile sites and genomic regions involved in cancers. Proc Natl Acad Sci U S A 2004;101:2999-3004.

10 Kim VN, Han J, Siomi MC: Biogenesis of small rnas in animals. Nat Rev Mol Cell Biol 2009;10:126-139.

11 Bartel DP: Micrornas: Target recognition and regulatory functions. Cell 2009;136:215-233.

12 Valencia-Sanchez MA, Liu J, Hannon GJ, Parker R: Control of translation and mrna degradation by mirnas and sirnas. Genes Dev 2006;20:515-524.

13 Garzon R, Calin GA, Croce CM: Micrornas in cancer. Annu Rev Med 2009;60:167-179.

14 Ding N, Wu X, He J, Chang L, Hu W, Li W, Wang J, Wang T, Zhou G: Detection of novel human mirnas responding to X-ray irradiation. J Radiat Res 2011;52:425-432.

15 Chang L, Hu W, Ye C, Yao B, Song L, Wu X, Ding N, Wang J, Zhou G: Mir-3928 activates atr pathway by targeting dicer. RNA Biol 2012;9:1247-1254.

16 Liu C, Gao F, Li B, Mitchel RE, Liu X, Lin J, Zhao L, Cai J: Tlr4 knockout protects mice from radiation-induced thymic lymphoma by downregulation of il6 and mir-21. Leukemia 2011;25:1516-1519.

17 Liu C, Zhou C, Gao F, Cai S, Zhang C, Zhao L, Zhao F, Cao F, Lin J, Yang Y, Ni J, Jia J, Wu W, Zhou L, Cui J, Zhang W, Li B, Cai J: Mir-34a in age and tissue related radio-sensitivity and serum mir-34a as a novel indicator of radiation injury. Int J Biol Sci 2011;7:221-233.

18 Wu N, Zhang C, Bai C, Han YP, Li Q: Mir-4782-3p inhibited non-small cell lung cancer growth via usp14. Cell Physiol Biochem 2014;33:457-467.

19 Lu J, Wen M, Huang Y, He X, Wang Y, Wu Q, Li Z, Castellanos-Martin A, Abad M, Cruz-Hernandez JJ, Rodriguez CA, Perez-Losada J, Mao JH, Wei G: C2orf40 suppresses breast cancer cell proliferation and invasion through modulating expression of $m$ phase cell cycle genes. Epigenetics 2013;8:571-583.

-20 Li D, Liu X, Lin L, Hou J, Li N, Wang C, Wang P, Zhang Q, Zhang P, Zhou W, Wang Z, Ding G, Zhuang SM, Zheng L, Tao W, Cao X: Microrna-99a inhibits hepatocellular carcinoma growth and correlates with prognosis of patients with hepatocellular carcinoma. J Biol Chem 2011;286:36677-36685.

21 Wu N, Liu C, Bai C, Han YP, Cho WC, Li Q: Over-expression of deubiquitinating enzyme usp14 in lung adenocarcinoma promotes proliferation through the accumulation of beta-catenin. Int J Mol Sci 2013;14:10749-10760. 
22 Wu N, Gu HJ, Li Q: Effects of antidiabetic drug metformin on the migration and invasion abilities of human pulmonary adenocarcinoma a549 cell line in vitro. J Thorac Dis 2010;2:76-80.

23 Grentzmann G, Ingram JA, Kelly PJ, Gesteland RF, Atkins JF: A dual-luciferase reporter system for studying recoding signals. RNA 1998;4:479-486.

24 Lewis BP, Burge CB, Bartel DP: Conserved seed pairing, often flanked by adenosines, indicates that thousands of human genes are microrna targets. Cell 2005;120:15-20.

-25 Friedman RC, Farh KK, Burge CB, Bartel DP: Most mammalian mrnas are conserved targets of micrornas. Genome Res 2009;19:92-105.

-26 Grimson A, Farh KK, Johnston WK, Garrett-Engele P, Lim LP, Bartel DP: Microrna targeting specificity in mammals: Determinants beyond seed pairing. Mol Cell 2007;27:91-105.

27 Garcia DM, Baek D, Shin C, Bell GW, Grimson A, Bartel DP: Weak seed-pairing stability and high target-site abundance decrease the proficiency of lsy- 6 and other micrornas. Nat Struct Mol Biol 2011;18:1139-1146.

28 Griffiths-Jones S, Grocock RJ, van Dongen S, Bateman A, Enright AJ: Mirbase: Microrna sequences, targets and gene nomenclature. Nucleic Acids Res 2006;34:D140-144.

29 Yarden Y, Sliwkowski MX: Untangling the erbb signalling network. Nat Rev Mol Cell Biol 2001;2:127-137.

-30 Fisher MC, Clinton GM, Maihle NJ, Dealy CN: Requirement for erbb2/erbb signaling in developing cartilage and bone. Dev Growth Differ 2007;49:503-513.

-31 Jullien N, Maudinet A, Leloutre B, Ringe J, Haupl T, Marie PJ: Downregulation of erbb3 by wnt3a contributes to wnt-induced osteoblast differentiation in mesenchymal cells. J Cell Biochem 2012;113:2047-2056.

32 Jullien N, Dieudonne FX, Habel N, Marty C, Modrowski D, Patino A, Lecanda F, Severe N, Marie PJ: Erbb3 silencing reduces osteosarcoma cell proliferation and tumor growth in vivo. Gene 2013;521:55-61.

-33 Guo Y, Xu F, Lu T, Duan Z, Zhang Z: Interleukin-6 signaling pathway in targeted therapy for cancer. Cancer Treat Rev 2012;38:904-910.

-34 Heinrich PC, Behrmann I, Haan S, Hermanns HM, Muller-Newen G, Schaper F: Principles of interleukin (il)6-type cytokine signalling and its regulation. Biochem J 2003;374:1-20.

35 Kollmann K, Heller G, Schneckenleithner C, Warsch W, Scheicher R, Ott RG, Schafer M, Fajmann S, Schlederer M, Schiefer AI, Reichart U, Mayerhofer M, Hoeller C, Zochbauer-Muller S, Kerjaschki D, Bock C, Kenner L, Hoefler G, Freissmuth M, Green AR, Moriggl R, Busslinger M, Malumbres M, Sexl V: A kinaseindependent function of cdk6 links the cell cycle to tumor angiogenesis. Cancer Cell 2013;24:167-181. 